This was published in Cognitive Linguistics.

Please cite as:

Van linden, An. 2010. From premodal to modal meaning: Adjectival pathways in English. Cognitive Linguistics 21 (3): 537-571.

\title{
From premodal to modal meaning: Adjectival pathways in English
}

\section{An Van linden*}

Abstract

This article approaches common topics in the diachronic literature on modal categories from the perspective of adjectives. It thus expands on what has been found for the better studied category of modal auxiliaries as regards sources of modal meaning and pathways of change. Most importantly, it proposes two new pathways from premodal to (dynamic) modal meaning, one followed by essential and vital, and one followed by crucial and critical. It also shows that in the four cases the development of dynamic meaning depends on the emergence of two semantic properties, viz. relationality and potentiality. Finally, this study makes it clear that the mechanisms driving the various semantic changes are not new, but rather have proved useful in explaining a varied set of developments. For the final semantic extension of the adjectives from dynamic to deontic meaning, for instance, the process of subjectification (Traugott 1989) will be invoked.

Keywords: modality; semantic change; adjectives; sources; premodal > modal;

dynamic > deontic 


\section{Introduction}

In the diachronic literature on modal categories, much attention has been devoted to verbal forms, especially to modal auxiliaries (e.g., Goossens 1983, 1999; Coates 1983; Plank 1984; Sweetser 1990: 49-75; Bybee et al. 1994; Hansen 1998, 2004; Van der Auwera and Plungian 1998; Diewald 1999; Traugott and Dasher 2002: Ch. 3). In general, accounts have focused on three topics, viz. (i) lexical sources of modal forms, (ii) pathways of change, and (iii) mechanisms of change, very often in the framework of grammaticalization. In this article, I will concentrate on another grammatical category expressing modal meaning, viz. adjectives. ${ }^{1}$ It will become clear that the adjectival data add new findings to what has been observed for the lexical and semantic sources of modal elements and their pathways of change from descriptive to deontic meaning. However, it will also appear that the mechanisms driving the semantic changes of the adjectives are not that new, but have been invoked already for a diverse set of changes in distinct conceptual domains (cf. Geeraerts 1997: 93102). Therefore, I will return to this topic only in the various case-studies of the adjectives (Section 4).

It is generally agreed that modal expressions ultimately derive from non-modal elements (e.g. Traugott 2006: 107). The English modal auxiliary can, for instance, has developed from the main verb cunnan 'know (how to)', just like the modal shall has developed from the main verb sculan 'owe' (Bybee et al. 1994: 183, 190; Traugott and Dasher 2002: 119). Typological studies have shown that these lexical sources are cross-linguistically recurrent for expressions of ability and obligation respectively (e.g. Bybee et al. 1994; Van der Auwera and Plungian 1998; Heine and Kuteva 2002: 327, 333). More specifically, for the latter notion, traditionally seen as part and parcel of deontic modality, the following sources have been proposed: (i) future-oriented 
need and desire (with lexical sources need, want), (ii) being or coming into being (with lexical sources be, sit, stand, [be]fall), (iii) possession (with lexical sources possess, have, get, obtain, catch, owe), (iv) positive evaluation (with lexical sources be fitting, good, mete [measure]) (Bybee et al. 1994: 182-183; Traugott and Dasher 2002: 118-119, Heine and Kuteva 2002: 333). Although the adjectives focused on in this article do not encode obligation, they can be used to express the conceptually related category of strong desirability, as in (1) (also included within the deontic domain by some authors, e.g. Nuyts 2006).

(1) But quite apart from mediation, it is essential that more explicit recognition is given in the Bill to the important role marriage counselling can play in exploring the possibility of reconciliation. (CB 1996, times)

It will become clear that not only essential, but also vital, crucial and critical derive from very different sources than the ones found for obligation among verbal forms.

In addition to the semantic and lexical sources of modal categories, diachronic studies devoted to the modal domain have concentrated on pathways of change. As noted by Traugott (2006: 110), these 'pathways', 'paths', 'clines', or 'chains' should be interpreted as macro-schemas accommodating overarching types of change (cf. Andersen 2001). These schemas typically include focal points, which indicate microsteps by which changes occur, like in ability > root possibility > epistemic possibility (for the English modal can, for instance). It is assumed that such micro-steps are instances of gradual change, with diachronic gradualness corresponding to synchronic gradience (see, e.g., Denison 2001). In principle, three types of pathways can be distinguished: (i) from premodal to modal meaning, (ii) from one modal to another 
modal meaning, and (iii), from modal to postmodal meaning. When reviewing the literature, it becomes apparent that especially paths of type (ii) have been focused on. Language-specific as well as cross-linguistic accounts have generally adduced evidence for the agent-oriented/root ${ }^{2}>$ epistemic pathway (e.g. Heine, Claudi and Hünnemeyer 1991; Bybee et al. 1994; Van der Auwera and Plungian 1998; Traugott and Dasher 2002: Ch. 3). ${ }^{3}$ Paths of type (iii) still have received some attention (e.g. Bybee et al. [1994: 212-225] on the development of "subordinating moods", and Van der Auwera and Plungian [1998: 104-110] on “demodalization”), but those of type (i) have hardly been investigated. In this article, I will detail the semantic development of four adjectives from their original non-modal meaning to dynamic meaning and further to deontic meaning. I will present two new pathways from premodal to (dynamic) modal meaning, each exemplified by two adjectives.

The structure of this article is as follows. Section 2 briefly describes the modal notions referred to in this study and discusses the data and the corpora used. Section 3 concentrates on the lexical sources of deontic adjectives. Section 4 discusses the semantic developments of essential, vital, crucial and critical. It distinguishes between the changes from premodal to modal meaning, and those within the modal domain. Whereas in the latter case the dynamic-deontic development mirrors that of modal verbs, the developments leading to dynamic meaning offer new insights. I argue that the development of this modal meaning involves (the emergence of) two properties in the semantic make-up of the adjectives, which are called 'relationality' and 'potentiality'. Relationality is needed to turn the adjective into a predicate of necessity that can link two concepts, for instance a part and a whole, or a condition and a goal. Potentiality is needed to ensure that the relationship established by the adjective is one of indispensability, which gives rise to dynamic meaning. Although 
all four adjectives differ in the way they develop these properties, it proves possible to generalize over the four cases and I propose two pathways of change from premodal to modal meaning. In Section 5, finally, I recapitulate the main findings and propose questions for further reflection.

\section{Modal notions and data}

The modal notions central to this article are dynamic and deontic modality. Dynamic modality traditionally involves ascribing an ability or capacity to the subject participant of a clause (e.g. von Wright 1951b: 28). However, this definition has been felt to be too narrow, and it has been extended to all indications of abilities/possibilities, or needs/necessities inherent in participants of actions (which are not necessarily syntactic subjects) or in situations (e.g. Palmer 1979: 3-4, Ch. 5-6, 1990: Ch. 5-6; Perkins 1983: 11-12; Nuyts 2005, 2006). ${ }^{4}$ It is especially the situational subtype that can be expressed by the adjectives studied here, as in (2).

(2) This should make you want to go to the toilet frequently. Although it may sting the first few times you go, this usually gets better the more water you pass. It is essential to keep emptying the bladder if you are to flush out the germs. (CB 1992, ukepehm)

Situational dynamic modality involves the indication of "a potential or a necessity/inevitability inherent in the situation described in the clause as a whole" (Nuyts 2006: 4). In (2), the speaker describes the need to keep emptying the bladder in order to flush out the germs (note the condition-goal paraphrase). Importantly, the speaker does not express his/her personal opinion, but rather a natural law-like truth: 
the need or necessity originates in the physical make-up of the human body. Example (2) thus expresses a necessity that is internal to the State of Affairs (SoA) described in the clause.

Deontic modality, in turn, has traditionally been defined in terms of obligation and permission (von Wright 1951a, 1951b: 36, 1971; Lyons 1977: 823-841; Kratzer 1978: 111; Palmer 1979: Ch. 4, 1986: 96-115; Goossens 1985: 204; Van der Auwera and Plungian 1998: 81). However, Nuyts (2006: 4) has proposed a more general definition as "an indication of the degree of moral desirability of the state of affairs expressed in the utterance", which does not necessarily involve obligation or permission. In fact, the adjectives studied never encode obligation or permission, but they can be used to express someone's (viz. of the attitudinal source) commitment to an SoA in terms of his/her moral principles. These principles are invariably external to the SoA assessed in the expression, as in (3).

(3) Herbert Daniels, the group's founder, believes that it is essential to overcome the social stigma of Aids, which often means that people with the virus lose their homes, jobs and families, and are effectively condemned to death by society. (CB 1990, bbc)

In (3), the (reported) speaker does not impose an obligation, but rather expresses his commitment to overcoming the social stigma of Aids on the basis of moral grounds. Unlike in (2), therefore, essential expresses SoA-external necessity in (3).

In addition to essential, illustrated in (1) to (3), this article focuses on three other adjectives that were borrowed into English with a non-modal descriptive sense, viz. vital, crucial and critical. These adjectives were searched for in the electronic version 
of the Oxford English Dictionary (OED) to find information on their etymology. In addition, I used its general quotation database, in which nearly all quotations are precisely dated and thus very helpful in tracking the semantic development of the adjectives in question. In addition to the OED, I also used the set of diachronic and synchronic corpora presented in Table 1 below, to corroborate the findings. It should be noted, though, that in some cases I found a considerable time lag between the first attestation of a use in the OED and its occurrence in the corpus data.

Table 1: The corpora used for each subperiod and their number of words

\begin{tabular}{lclc}
\hline Subperiod of English & Time span & \multicolumn{1}{c}{ Corpus } & $\begin{array}{c}\text { Number } \\
\text { of words } \\
\text { (million) }\end{array}$ \\
\hline $\begin{array}{l}\text { Middle English } \\
\text { (ME) }\end{array}$ & $\begin{array}{c}1150- \\
1500\end{array}$ & $\begin{array}{l}\text { Penn-Helsinki Parsed Corpus of Middle } \\
\text { English, Second Edition (PPCME) }\end{array}$ & 1.16 \\
\hline $\begin{array}{l}\text { Early Modern English } \\
\text { (EModE) }\end{array}$ & $\begin{array}{c}1500- \\
1710\end{array}$ & $\begin{array}{l}\text { Penn-Helsinki Parsed Corpus of Early } \\
\text { Modern English (PPCEME) }\end{array}$ & 1.79 \\
\hline $\begin{array}{l}\text { Late Modern English } \\
\text { (LModE) }\end{array}$ & $1710-$ & $\begin{array}{l}\text { Corpus of Late Modern English texts } \\
\text { (Extended version) (CLMETEV) } \\
\text { (De Smet 2005, 2008) }\end{array}$ & 15.01 \\
\hline $\begin{array}{l}\text { Present-day English } \\
\text { (PDE) }\end{array}$ & $\begin{array}{c}\text { roughly } \\
1990-\end{array}$ & $\begin{array}{l}\text { Collins COBUILD corpus (CB) } \\
\text { (only British subcorpora) }\end{array}$ & 42.10 \\
\hline
\end{tabular}

\section{Sources of deontic modality}

Several cross-linguistically recurrent sources have already been proposed for the notion of obligation (for an inventory, see Section 1). Among these, expressions of positive evaluation are relevant to English, as complex constructions with adjectives such as appropriate can be used to express deontic meaning, as in (4). However, they express a weaker degree of desirability than the adjectives studied here.

(4) You can indulge the shortcomings of a friend a certain number of times and then, unwittingly, they go over the limit. You tot everything up and, (...) there 
comes a point when you decide that in total they are unforgivable and can no longer be overlooked. (...) Sometimes it may be wholly appropriate not to forgive or forget. (CB 1993, ukmags)

A set of such 'weak(er)' English adjectives can even be traced further back to other sources listed in Section 1. The adjectives proper and appropriate, for instance, etymologically involve the notion of possession (cf. OED, s.v. proper and appropriate). ${ }^{5}$ The adjectives fitting (and possibly also fit) and meet, in turn, relate to the notion of measure (cf. OED, s.v. fitting, fit and meet). ${ }^{6}$

However, it has also been acknowledged that the inventory of sources for the notion of obligation is not exhaustive (e.g. Van der Auwera and Plungian 1998: 91). The adjectives I am concerned with here, which express a strong degree of desirability in the deontic domain, derive from sources very different from the ones mentioned above. For example, essential, borrowed into English from Latin in the $15^{\text {th }}$ century, is an adaptation of the Late Latin word essentialis, which in turn derives from the noun essentia 'essence' (OED, s.v. essential). Vital, which entered the English language in the $14^{\text {th }}$ century, also derives from a noun, viz. Latin vita 'life' (note that according to the OED its precise etymology is not very clear: either it is adopted from Old French vital, or it is an adaptation of the Latin form vitalis). ${ }^{7}$ Crucial and critical ultimately derive from nouns as well. Crucial, borrowed from French in the $18^{\text {th }}$ century, is based on the Latin form crux 'cross' (OED, s.v. crucial). Critical, finally, goes back

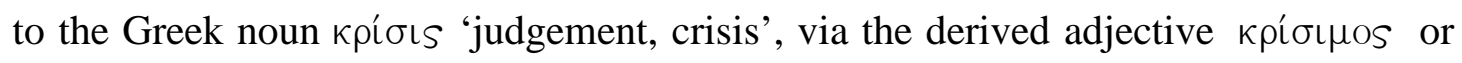
крıтıкós (Liddell et al. 1951 [1924]: i 997a), which was first borrowed into Latin as criticus, and in the $16^{\text {th }}$ century into English as critic (OED, s.v. critic and critical). Morphologically, the adjectives studied thus all are derivations from a nominal base. 
Semantically, the nominal sources refer to either abstract notions (essence, life and judgement/crisis) or concrete entities (cross), which are not included in the set of sources given above. The adjectives essential, vital, crucial and critical therefore present us with additional sources for deontic meaning. ${ }^{8}$

\section{Pathways of semantic change}

This section concentrates on the semantic development of the four adjectives studied here. In Section 4.1, I will discuss changes from premodal to modal meaning, which have been largely under-researched so far (cf. Section 1). I will present two new pathways of change towards dynamic meaning, which share the emergence of two semantic properties, viz. relationality and potentiality. In Section 4.2, I will discuss a change within the modal domain common to all four adjectives, viz. that from dynamic to deontic meaning, which has also been observed for modal auxiliaries such as can, must and may. In general, I will show that the development of the lexical items cannot be dissociated from the constructions they appear in, which are broadly understood here as including patterns of co-occurrence and patterns of (prepositional or clausal) complementation. As with the modal auxiliaries, the lexicon-syntax interface thus plays an important role in the semantic development of the adjectives as well. It will also turn out that the mechanisms driving the semantic changes are not specific to the adjectival developments either.

\subsection{Changes from premodal to modal meaning}

If we take a closer look at the semantic development of essential, vital, crucial and critical, we can distinguish between two pathways from premodal to modal meaning. I will first discuss the developments of essential (Section 4.1.1) and vital (Section 
4.1.2), and I will argue that these mark a first pathway to dynamic meaning (Section 4.1.3). Then I will present the developments of crucial (Section 4.1.4) and critical (Section 4.1.5), which came later into the English language (see Section 3), and propose a second pathway on the basis of these findings (Section 4.1.6). Both pathways will be described in terms of the properties of relationality and potentiality, which are the semantic prerequisites for dynamic meaning to emerge. In addition, as suggested by a referee, it will become clear that the adjectives comply with the tendency noted by Paradis (2001: 58) for non-gradable items to develop into gradable ones.

4.1.1 Essential from premodal to dynamic meaning. ${ }^{9}$ This section concentrates on the semantic developments of essential towards dynamic meaning. As proposed in Table 2 below, we can hypothesize three stages, which are the result of two semantic changes. The first change is that from its original meaning to a relational type of meaning, which is termed 'defining necessity'. The second change is that to (situational) dynamic modal meaning, for which the development of the feature of potentiality is crucial. It will also become clear that the main driving factors of the changes are patterns of co-occurrence.

Table 2: The development of essential from premodal to modal meaning (cf. Van linden et al. 2008: 240, Table 2)

\begin{tabular}{lcccc}
\hline Stages & $\rightarrow$ & $\begin{array}{c}\text { stage 1: } \\
\text { original meaning }\end{array}$ & $\begin{array}{c}\text { stage 2: } \\
\text { defining necessity }\end{array}$ & $\begin{array}{c}\text { stage 3: } \\
\text { dynamic meaning }\end{array}$ \\
\hline First attestation & $\rightarrow$ & $c 1440$ & 1596 & 1618 \\
\hline Meaning and & & 'being such by its & 'constituting the true \\
true nature' & nature of' & 'indispensable for' \\
examples & $\rightarrow$ & $(5)$ & $(6)-(8)$ & $(9)-(11)$ \\
\hline relationality & - & + & + \\
potentiality & - & - & + \\
\hline
\end{tabular}


As can be seen in Table 2, the original meaning of essential in English is not relational, nor potential. It can be paraphrased as 'being such by its true nature', or 'being such in the true sense of the word'. The OED gives "that is such by essence, or in the absolute or highest sense" (OED, s.v. essential). An example is given in (5).

For pe souerayneand pe Escencyalle Ioyes in pe lufe of Godd for the sovereign and the essential joy is in the love of God by hym-selfe and for hym-selfe, and pe secundarye es in comonynge by himself and for himself, and the secondary is in communing and byhaldynge of Aungells and gastely creaturs. and beholding of angels and ghostly creatures 'For the sovereign and the essential joy is in the love of God by himself and for himself, and the secondary (joy) is in the communing and the beholding of Angels and ghostly creatures' (PPCME c1440 ?Rolle pi ioy [Thrn] 17)

In (5), the adjective essential, like secondary, indicates a type of joy. In this sense, it functions as a classifier and not as an attribute of the noun joy. ${ }^{10}$ Semantically, classifiers denote a subtype of the more general type referred to by the head noun, and "tend to be organized in mutually exclusive and exhaustive sets" of that general type (Halliday 1994: 185). In fact, the two types of joy in (5) are opposed to each other, and thus presented as mutually exclusive and exhaustive sets of joy: essential joy (meaning 'true', 'basic', 'substantial' or 'primary' joy) versus secondary joy (meaning 'derived', 'accidental' joy). 
The first semantic extension of essential on its pathway to dynamic meaning involves the development of relational meaning (cf. Table 2). This type of meaning is illustrated in (6) below.

(6) Sensibility and a locomotive faculty are essentiall to every living creature. (OED 1656 Bramhall, A replication to the bishop of Chalcedon i. 5)

In (6), sensibility and a locomotive faculty are said to constitute the essence of every living creature. This use of essential is relational because it does not indicate a type of something (e.g., a type of joy as in [5]), but serves to relate two concepts, viz. sensibility/locomotion and life. Whereas the original sense of essential is still taxonomic, in that it applies to types, the relational meaning is clearly partonomic, in that it applies to parts in relation to a whole. This change is also reflected in the syntactic potential of the adjective: it is not a classifier, but now functions as an attribute in predicative position, and it can take a prepositional complement. In addition, it has changed from a non-gradable to a gradable item: in examples such as (6) essential can take totality modifiers such as absolutely (cf. Paradis 2001: 50-53).

It has been shown that the diachronic bridge between the original classifier use in (5) and the later relational use in (6) can be found in structures in which the classifier co-occurs with relational nouns like property, attribute or part (Van linden et al. 2008: 232-234), as in (7) and (8) below. ${ }^{11}$

(7) Heate is the essentiall propertie of fire (OED 1620 Granger, Syntagma logicum, or the divine logike 66) 
In these examples, essential functions as a classifier with the relational nouns property and attribute, which denote a part within a larger whole. This pattern of cooccurrence with relational nouns is decisive for the development of relational meaning of the adjective itself: with relational nouns, the paraphrase proposed for the original use of essential in (5) cannot be applied anymore. In (7), for instance, essentiall propertie does not mean 'that is a property in the true sense of the word', or 'that is a property by its true nature'. Rather, the part-whole relationship in the background of property provides a better paraphrase: 'a property of the essence of fire', or 'a property constituting the essence of fire'. In this sense, it can be argued that relational nouns like property or attribute, which are based on a part-whole or inclusion relationship, are semantically permeable and therefore able to transfer their relational property to the adjectives that classify them.

The semantic permeability of the relational nouns actually implies that the meaning of essential in expressions such as (7) and (8) is relational as well. In (7), for instance, essential links heat with fire, as heat is said to constitute the essence of fire, and in (7), it links mercy with God, as mercifulness is argued to constitute the essence of God. Thus, heat is essential to fire, and mercy is essential to God. In (7) and (8), then, essential establishes a relation of inclusion between two concepts, just like in (6). As can be seen in (6), later relational uses of essential do not necessarily involve relational nouns: it has merely been argued that co-occurrence with relational nouns (i.e. classifier relational uses) is a facilitating factor that forms a diachronic bridge between classifier non-relational uses and non-classifier relational uses. 
As indicated in Table 2, the type of meaning expressed by relational uses of essential is called 'defining necessity' (cf. Van linden et al. 2008: 234). In fact, if certain properties or attributes are said to constitute the essence of something, they are necessary to it, for otherwise we might be dealing with just something else. Importantly, this type of necessity differs from the classic dynamic-modal type of necessity, i.e. the necessity we experience when something is needed for a certain purpose. The second semantic change in the development of essential then is the extension from the sense of defining necessity to that of dynamic necessity, in which the property of potentiality plays a key role (cf. Table 2).

What distinguishes the two types of necessity is the notion of definition. The first type of necessity obviously is defining in nature, whereas the second type is not. Example (7), for instance, can be paraphrased as 'fire is (necessarily) hot', and (8) as 'God is (necessarily) merciful'. In these paraphrases, the predicates do not add any new information to the subject, but rather define it. Being hot, for example, is a defining feature of fire. In this sense, the paraphrases are analytical propositions, in which subject and predicate are linked by virtue of their intension. Furthermore, what is regarded as necessary in a defining way (e.g., mercy as necessary to God in [8]) is intrinsically present in it. ${ }^{12}$ Finally, defining necessity applies to all instances of the type designated by the head noun to which something is said to be necessary: all fires, for instance, are hot.

Dynamic (modal) necessity, on the other hand, has very different semantic characteristics. Consider the following example. 
(9) And practice, though essential to perfection, can never attain that to which it aims, unless it works under the direction of principle. (CLMETEV 1776 Reynolds, Seven discourses on art)

In (9), 'practice' is not defining of 'perfection'. The example is a synthetic proposition, in which the predicate is not linked to the subject by virtue of its intension, but adds new information about the subject. Furthermore, dynamic necessity does not really signal an inherent presence, such as the presence of mercy in God in (8), but rather the absence of something that is desirable for a particular purpose, such as 'practice' in (9). The subtype of dynamic meaning involved here thus is situational in the sense defined in Section 2: the necessity of 'practice' is inherent in the situation of reaching perfection, with the necessity being indicated on the basis of SoA-internal grounds. Finally, as this type of necessity is not defining in nature, it does not necessarily apply to all instances of the type designated by the head noun to which something is said to be essential.

The semantic extension of essential from the sense of defining necessity to that of dynamic necessity can be attributed to the emergence of an element of potentiality. Corpus examples such as (9) show that the potential element can originate in the fact that the element to which something is said to be essential is a potential action, viz. reaching the state of perfection. Clearly, the action representing the goal is potential: it has not yet been realized, but it can be realized at some point in the future.

However, the earliest constructions in which potentiality emerges are expressions in which the element to which something is said to be essential is modified by an evaluative adjective. They appear in the early $17^{\text {th }}$ century, not much later than the 
first relational (but non-potential) uses (1596). Examples are given below; example (10) is the first attestation in the OED.

(10) It is an essentiall property of a man truly wise, not to open all the boxes of his bosome. (OED a1618 Ralegh, Remains, viz. Maxims of state, Advice to his son [1664] 89)

(11) Government is essential to formed and regular Societies. (OED 1681-1686 Scott, The christian life [1747] III. 386)

In these examples, the nouns to which a particular feature is said to be essential (man in [10], societies in [11]) are modified by evaluative adjectives. These adjectives indicate that the predication of being essential does not apply to all instances of the type designated by those nouns, but only to a subjectively defined subset of them. The type of subjectivity intended here is the one involving the speaker's evaluation of an entity, i.e. the description of a content based in the speaker's subjective attitude towards the situation (De Smet and Verstraete 2006: 385). ${ }^{13}$ This type of subjective meaning gives rise to potential meaning. In (10), for instance, the property of not opening all the boxes of your bosom is said to be an essential property of truly wise men (only), so not of just every man. The property actually serves as a criterion for a man to be taken up in the privileged subset of truly wise men, or, in other words, if you want to be considered a truly wise man, you should not open all the boxes of your bosom. Example (11) can in turn be paraphrased as 'in order for a society to be considered formed and regular, it should have government, or it should be governed'. These condition-goal paraphrases make it clear that evaluative adjectives bring with them the notion of dynamic (situational) necessity. The examples (9) to (11) thus show that the extension of essential to evaluative contexts and contexts of potential 
action implies a semantic extension of the adjective: the relationship established by it has been extended from one of intrinsic inclusion (in contexts of defining necessity) to one of indispensability (in contexts of dynamic necessity).

In conclusion, in the development from premodal to (dynamic) modal meaning, essential first acquired relational meaning through co-occurrence with relational nouns, and came to express defining necessity. Later on, co-occurrence with evaluative adjectives and potential actions drove the development of potential meaning, and the extension from intrinsic inclusion to indispensability or dynamic necessity. It is not surprising that the earliest examples of potential meaning were found in evaluative contexts, as these are still close to defining contexts because of the inclusion relationship between the two entities linked by essential (e.g. properties of men in [10]). Contexts of potential action, by contrast, are both diachronically (cf. [9]) and semantically further 'removed' from defining contexts, because they have given up the inclusion relationship at all.

4.1.2. Vital from premodal to dynamic meaning. In the semantic development of vital to dynamic meaning, we can also distinguish between three stages as the result of two changes. As shown in Table 3, the first stage involves its original meaning, which is already relational, but yet non-modal. I will discuss three different subsenses; the first semantic change involves the generalization of one specific subsense, viz. that in the collocation vital parts, which gives rise to the meaning of defining necessity (like essential in its second stage). The second semantic change is that to dynamic meaning, in which again the property of potentiality emerges. Like in the case of essential, this change occurs through the extension to contexts of evaluation and potential action. However, the chronology of the first attestations of the senses in 
stages 2 and 3 requires us to regard the development sketched here as merely a hypothesis.

Table 3: The development of vital from premodal to modal meaning

\begin{tabular}{lcccc}
\hline Stages & $\rightarrow$ & $\begin{array}{c}\text { stage 1: } \\
\text { original meaning }\end{array}$ & $\begin{array}{c}\text { stage 2: } \\
\text { defining necessity }\end{array}$ & $\begin{array}{c}\text { stage 3: } \\
\text { dynamic meaning }\end{array}$ \\
\hline First attestation & $\rightarrow$ & 1386 & 1647 & 1619 \\
\hline Meaning and & & 'associated with life & 'essential to'; & 'indispensable for' \\
or the heart'; & 'constituting the \\
examples & $\rightarrow$ & 'essential to life' & essence of' \\
& & $(12)-(15)$ & $(16)-(17)$ & $(18)-(19)$ \\
\hline relationality & & + & + & + \\
potentiality & - & - & + \\
\hline
\end{tabular}

In its earliest attestations in the OED and the historical corpora, vital is used in three distinct senses. The data do not provide a decisive answer as to which sense is the original one in English, or whether these senses developed out of one another. As these questions are not immediately relevant to the development of modal meaning, they are not discussed in further detail.

The first attestation of vital dates from 1386, and involves the general sense of 'associated with life'. The OED gives a more specific definition: "consisting in, constituted by, that immaterial force or principle which is present in living beings or organisms and by which they are animated and their functions maintained" (OED, s.v. vital). The example is given in (12) below.

(12) In hise armes two The vital strengthe is lost, and al ago. in his arms two the vital strength is lost, and all agone 'In his two arms the vital strength is lost and all gone.' (OED c1386 Chaucer, Knight's Tale 1994) 
A second sense of vital appears not much later in the OED data (1450), and is also covered by the 'associated with life' paraphrase. In this case also, a more specific definition can be put forward, in which vital is associated with the physiology of the ancient Greek physician Galen (129-199 AC) (TLF XVI: 1210a). Building on Plato's tripartite nature of the soul, consisting of a vegetative, sensitive and rational soul (Knoeff 2004: 419), Galen distinguished between three systems, each of which is located in different organs and has a distinct set of virtues and faculties (Siraisi 1990: 107). In later Galenic thought, these systems were called the natural, vital and animal system, the principal parts of which are the liver, heart and brain respectively (Siraisi 1990: 107-108). Galenic physiology and pneumatology persisted into the $17^{\text {th }}$ century (Forrester 2002), which is reflected in the OED data. In the Middle and Early Modern English data, vital is found in collocation with nouns such as spirit(s), blood, heat, virtue and faculty, with the specific meaning of 'associated with the heart'. In these collocations, as in (13), vital does not assign a gradable quality, but rather functions as a classifier, as it indicates a specific subtype of a more general type (e.g. spirit), in opposition with natural and animal.

(13) The Spirit Vitall in the Hert doth dwell, The Spirit Naturall... the spirit vital in the heart does dwell, the spirit natural in the Liver..., but Spirit Animall dwelleth in the Braine. in the liver, but spirit animal dwells in the brain 'The vital spirit dwells in the heart, the natural spirit in the liver, but the animal spirit dwells in the brain.' (OED 1477 Norton, The ordinall of alchimy [1652] 82) 
It can be argued that in the sense of 'associated with life (or the heart)', vital already has a relational meaning (cf. Table 3): it evokes a relationship with 'life'. In this sense, it can be paraphrased as 'essential to life', with essential used in a defining way. Vital strength, for instance, is a strength that is intrinsically present in life, or more specifically in living creatures and organisms. Likewise, the vital spirit is intrinsically present in life. At least in that particular Weltanschauung, it constitutes the essence of life, and every living human being has it by definition. The senses of vital in vital strength and vital spirit thus both imply a relationship of intrinsic inclusion.

The third non-modal sense of vital is found in collocations with the relational noun $\operatorname{part}(s)$, and its first example in the OED dates from 1565. Arguably, this collocation was used in a Galenic and a modern sense. In the Galenic sense, the term vital parts referred to the organs of the Galenic vital system, viz. the organs in the thoracic cavity and the arteries (Siraisi 1990: 107). This sense is illustrated in example (14) below, in which the vital parts are opposed to the parts of the natural system, which were also called the 'nourishing parts'. Again, vital is used as a classifier, indicating a type of parts. In the modern sense, the referents of the collocation do not belong to the vital system only, but also to the animal and natural system. In this sense, vital also functions as a classifier. However, it is not opposed to natural/nourishing or animal, as in the Galenic sense, but rather to non-vital. Vital parts are organs without which we cannot live, such as the heart, lungs, brains and liver, whereas non-vital parts are those which can be missed, such as the milt, uterus and eyes. This modern sense is illustrated in example (15), and is clearly of a later date than the Galenic example. However, both senses can be paraphrased by 'essential to life', with essential used in a defining way. According to the Galenic 
Weltanschauung on the one hand and that of modern medicine on the other, these parts are intrinsically present in life, or, to put it differently, without these parts, there is no life.

(14) There is a partition called diaphragma by the Gracians, which separateth the instruments of the vital partes, from the nourishing parts. (OED 1594 Bowes, De La Primaudaye's French academie II. 220)

(15) The Vital Parts are the Heart, Brain, Lungs and Liver. (OED 1696 Phillips, The new world of English words: or, a general dictionary [ed. 5] s.v. vital)

The first semantic change of vital involves semantic generalization, in which vital loses its connection with 'life' and comes to express defining necessity (cf. Table 3). ${ }^{14}$ This generalization starts from its collocation with parts, and extends the relationship of intrinsic inclusion within 'life' to that of intrinsic inclusion within basically anything that is more or less composite in nature. The hypothesis that the generalization occurred prior to rather than simultaneous with the development of potential meaning is suggested by examples in which vital is found with nouns referring to abstract concepts that are fairly homogeneous in substance, much like the relational non-potential examples found with essential, viz. (7) and (8) above. Examples with vital are given in (16) and (17). We can note that they also show structural reflections of its relational meaning: the elements to which something is said to be vital are coded by of-PPs (the same goes for [18] below). In addition, vital has become gradable, as it can combine with totality modifiers such as absolutely (cf. Paradis 2001: 50-53). 
(16) Their submiss Reverence to their Princes being a vital part of their Religion; (OED 1647 Clarendon, The history of the rebellion and civil wars in England I. §76)

(17) If these he has mentioned be the substantial and vital parts [of his theory, OED]. (OED 1698 Keill, An examination of Dr. Burnet's Theory of the earth [1734] 181)

In these examples, vital co-occurs with the relational noun part, but it bears no relation to 'life' anymore. Instead, vital is used in its generalized sense, as it refers to essential parts of a religion or theory. It can be argued that vital is used here in a defining way, as the religion in (16) and the theory in (17) would not be the same anymore if the vital parts were changed or removed. In other words, these parts are intrinsically present in the religion or theory, and constitute their essence.

The second semantic change of vital involves the development of the property of potentiality (cf. Table 3). Like in the case of essential, this property - and hence, dynamic meaning - first emerges in examples in which the noun to which something is said to be vital is modified by an evaluative adjective. ${ }^{15}$ As discussed in Section 4.1.1, such adjectives indicate that the predication does not apply to all instances of the type designated by that noun, but only to a subjectively defined subset of these. An example is given below.

(18) The three vital circumstances of a well-ordered Action, Person, Time and Place. (OED 1619 Lushington, The resurrection rescued from the soldiers' calumnies [1659] 70) 
This example is similar to that with essential and an evaluative adjective, like in (10) and (11) above. In (18), the three circumstances listed are essential or necessary only to a potential or subjectively defined subset of actions, viz. well-ordered actions. In other words, in order for an action to be considered well-ordered, it should be characterized by the circumstances of person, time and place. This condition-goal paraphrase suggests that the evaluative adjective well-ordered imposes a potential interpretation on vital. It should also be noted that here the relationship established by vital is not one of intrinsic inclusion, but rather one of indispensability.

Later, the property of potentiality is also found in examples in which some element is said to be vital to a particular potential action. Example (19) bears a close resemblance to (9) above, in which essential is used with a potential action.

Hence it was that the raising of the siege of Gibeon...was so vital to the conquest of Canaan. (OED 1856 Stanley, Sinai and Palestine in connection with their history iv. 215)

In (19), raising the siege of Gibeon is said to have been vital or necessary in order to conquer Canaan. Again, the condition-goal paraphrase and the SoA-internal character of the necessity make it clear that the type of meaning involved is situational dynamic modality. Clearly, the relation that vital establishes is one of indispensability. The meaning of vital has thus been extended from defining to dynamic necessity in the course of the $17^{\text {th }}$ century.

To conclude, it can be hypothesized that the development of vital from premodal to modal meaning first involved semantic generalization. The three subsenses found in the earliest attestations of vital all already implied a relationship of intrinsic 
inclusion within 'life', which can be explained by the etymology of vital (ultimately based on Latin vita, 'life'). The semantic generalization preserved this type of relationship and yielded the meaning of essential used in a defining way. The connection with 'life', however, got lost. In a second change, driven by patterns of cooccurrence with evaluative adjectives and potential actions, vital developed dynamic meaning, involving the property of potentiality and a relationship of indispensability instead of intrinsic inclusion. Like in the case of essential, evaluative contexts appeared earlier than those with potential actions. Again, therefore, the data have shown that the properties of relationality and potentiality are the semantic conditions of the development of dynamic meaning.

4.1.3 A first pathway to dynamic meaning: essential and vital. From the previous discussions, we can infer that the semantic developments of essential and vital show more similarities than differences. They thus allow us to propose a first pathway to dynamic meaning, which is visualized in Figure 1.

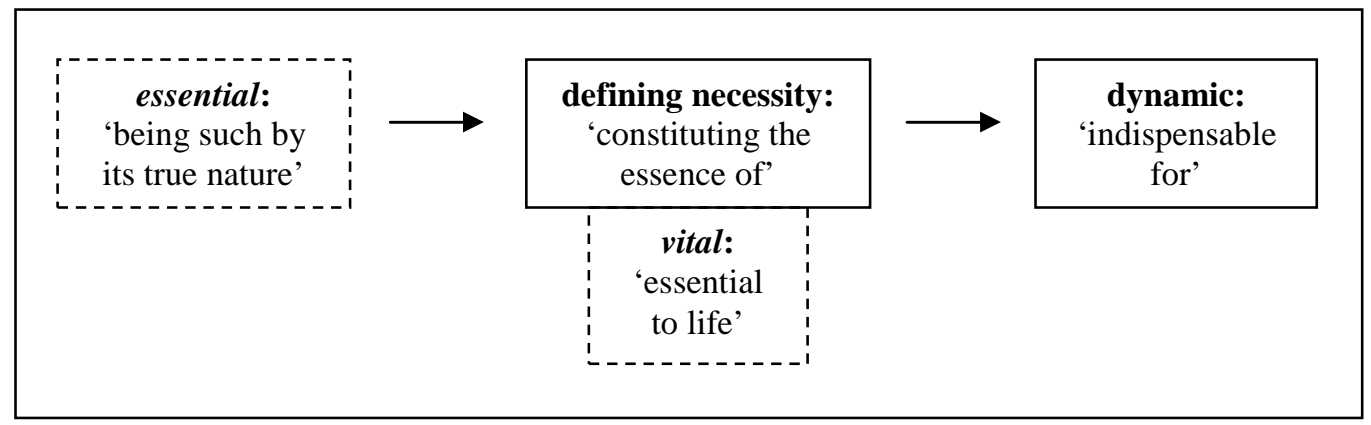

Figure 1: The first pathway to dynamic meaning: essential and vital

As can be seen in the figure, the main difference between the two concerns the beginning of the pathway. Remember that in its original meaning essential is nonrelational, whereas vital does not have a non-relational stage. However, both 
adjectives share a stage of defining necessity and later develop the meaning of dynamic necessity. In both cases, the development of this modal meaning involves first patterns of co-occurrence with evaluative adjectives, and later contexts of potential actions. The adjectives essential and vital therefore present us with a first pathway to dynamic meaning via the notion of defining necessity. In the following sections, I will put forward a second pathway, for which the adjectives crucial and critical are exemplary. Both pathways not only mark a development from descriptive to modal items, but also from non-gradable to gradable items.

4.1.4 Crucial from premodal to dynamic meaning. ${ }^{16}$ This section focuses on the development from premodal to modal meaning of crucial, in which four stages can be recognized, which are, however, not as clear-cut as is the case for essential and vital. Table 4 hypothesizes what these stages may look like.

Table 4: The development of crucial from premodal to modal meaning (cf. Van linden et al. 2008: 244, Table 3)

\begin{tabular}{|c|c|c|c|c|c|}
\hline Stages & $\rightarrow$ & $\begin{array}{c}\text { stage } 1: \\
\text { original } \\
\text { meaning }\end{array}$ & $\begin{array}{c}\text { stage } 2: \\
\text { metaphorized } \\
\text { meaning }\end{array}$ & $\begin{array}{c}\text { stage } 3: \\
\text { collocational } \\
\text { meaning } \\
\end{array}$ & $\begin{array}{c}\text { stage } 4: \\
\text { dynamic } \\
\text { meaning }\end{array}$ \\
\hline First attestation & $\rightarrow$ & 1706 & 1830 & 1830 & 1869 \\
\hline $\begin{array}{l}\text { Meaning and } \\
\text { examples }\end{array}$ & $\rightarrow$ & $\begin{array}{l}\begin{array}{c}\text { 'cross- } \\
\text { shaped' }\end{array} \\
(20)-(21) \\
\end{array}$ & $\begin{array}{l}\text { 'like (at) a } \\
\text { finger-post' } \\
(22)\end{array}$ & $\begin{array}{c}\text { 'necessary to } \\
\text { decide between } \\
\text { two hypotheses' } \\
(22)\end{array}$ & $\begin{array}{l}\text { 'decisive for'; } \\
\text { 'important for' } \\
(23)-(24)\end{array}$ \\
\hline relationality & & - & - & + & + \\
\hline potentiality & & - & - & + & + \\
\hline
\end{tabular}

It will become clear that the distinction between the second and third stage is not hard and fast. In fact, these two stages coincide temporally due to the first semantic change, which is a metaphorical projection. I have disentangled these stages to be able to assign the same configuration of semantic properties to the source and target 
meaning of the metaphor. The second change, which is driven by semantic generalization, leads to the development of dynamic meaning.

As the original meaning of crucial in English, the OED (s.v. crucial) mentions 'cross-shaped' or 'in the form of a cross'. Its first attestations in the OED are given below.

(20) Crucial Incision, the cutting or lancing of an Impostume or Swelling cross wise. (OED 1706 Phillips, The new world of English words: or, a general dictionary [ed. Kersey] s.v. Incision)

(21) The bursal and crucial ligaments were in their natural order. (OED 1751 Phil. Trans. XLVII. xxxvii. 261)

Both in (20) and (21), crucial functions as a classifier. In (20), it indicates a specific type of incision in the form of a cross, as opposed to a linear incision. In (21), crucial denotes a sub-class of ligaments, viz. those in the knee-joint that cross each other in the form of a Saint Andrew's cross and connect the femur and tibia, as opposed to the bursal ligaments, which cross the bursa (OED, s.v. crucial and bursal). In both cases, crucial indicates a subtype of the general type of the head noun, and does not attribute a gradable quality to the NP referent. More generally, the OED database does not contain any predicative or graded uses of crucial in its original meaning. It is clear that crucial in the sense of 'cross-shaped' or 'cross-like' is non-relational, since it does not link two concepts, and non-potential, since it does not involve a potential event or the potential presence of an entity (cf. Table 4).

The first semantic change of crucial on its way to dynamic meaning involves metaphorical projection. It is commonly accepted that the basis of this metaphorical 
extension was laid in the work of Francis Bacon (1561-1626) (OED, s.v. crucial; FEW II2: 1382b; TLF VI: 559; Klein 1971: 178; Barnhart 1988: 238a). In his very influential Novum Organum (1620), written in Latin, Bacon coined the phrase instantia crucis 'crucial instance', which he explained as a metaphor derived from crosses that are placed at bifurcations of the road and indicate where each road will lead. Crucial instances are places where the scientist or thinker in general has to make a decision, as much as finger-posts are places where the traveller has to decide which way to $\mathrm{go}^{17}$ (the Latin word crux at that time had developed the meaning of 'a guidepost that gives directions at a place where one road becomes two' [OED, s.v. crucial; FEW II2: 1380a]). ${ }^{18}$ Bacon thus mapped the more concrete domain of travelling onto the more abstract domain of thinking. Robert Boyle (1627-1691) and Isaac Newton (1642-1727) built on this metaphor and used the term experimentum crucis to refer to the experiment performed to decide between two rival hypotheses (OED, s.v. crucial). Although the studies of the scientists mentioned were written in the $17^{\text {th }}$ or early $18^{\text {th }}$ century (some in Latin), the specific phrases with the adjective crucial appeared in English only in the $19^{\text {th }}$ century. ${ }^{19}$ The earliest example is given in (22) below.

What Bacon terms crucial instances, which are phenomena brought forward to decide between two causes, each having the same analogies in its favour. (OED 1830 Herschel, A preliminary discourse on the study of natural philosophy II. vi. 150)

The definitions of crucial instance (in [22]) and crucial experiment (described above) make it clear that these fixed phrases have relational and potential meaning as a 
whole, since the consideration of a 'finger-post-like' type of instance or the performance of such a type of experiment is necessary in order to decide between rival hypotheses, and ultimately to resolve the intellectual crisis. (Note that crucial functions as a classifier of its collocates.) Arguably, it is only in the specific collocations with instance and experiment that crucial has relational and potential meaning, which is another reason why Table 4 distinguishes between stages 2 and 3 . In any case, the condition-goal paraphrases imply that the collocations involve dynamic situational necessity, just like essential and vital in their third stage.

The second semantic change takes place when the use of crucial is extended to other contexts than the collocations with instance and experiment, and concomitantly, the specific meaning of 'necessary to decide between two hypotheses' is generalized to 'decisive for' or 'important for' (cf. Table 4). Whereas crucial only has this specific meaning in the collocations with instance and experiment, in which it functions as a classifier, it retains a more general meaning of 'important' or 'decisive' when used in modifying other nouns. Semantically, in such other contexts, it is crucial itself that has relational and potential meaning, and not the combination of the adjective and the noun. This is structurally reflected by the occurrence of complements (see [23] and [24]). Syntactically, it no longer functions as a classifier, but as an attribute: it is gradable, and it can be used in predicative position (see [24]). Example (23) illustrates the semantic generalization of crucial. Even if it modifies the noun experiments, we can still argue for a general attribute reading, since the potential action to which the experiment is considered crucial needs to be expressed; if crucial experiments had been used in its specific collocational sense, the for-complement would have been redundant. The type of relationship established by crucial is one of decisive importance or determining influence. 
(23) Crucial experiments for the verification of his theory. (OED 1869 Martineau, Essays philosophical and theological II. 134)

Like in the case of essential and vital, potential contexts such as in (23) are a prerequisite for dynamic modal meaning. A similar example is given in (24).

(24) It is crucial that the blocking device, (...), is deposited at this point to ensure that the tubes are rendered impassable. (CB 1996, times)

In (24), which is construed with an extraposed that-clause, the blocking device has to be deposited at a certain point in order to ensure that the fallopian tubes are rendered impassable. The action of depositing is necessary on SoA-internal grounds, that is, for the proper blocking of the tubes (in a sterilization operation). Examples (23) and (24) make it clear that after metaphorical projection and semantic generalization crucial can be used in dynamic utterances expressing a situation-internal necessity.

In summary, in its development from premodal to modal meaning, crucial starts with the non-relational and non-potential meaning of 'cross-shaped'. It then develops both types of meaning at once through metaphorical projection, brought about by Bacon's collocation crucial instance. In a process of semantic generalization, crucial loses the specific collocational meaning of 'necessary to decide between two hypotheses', and comes to mean 'decisive for'. In this meaning, it expresses dynamic necessity, like essential and vital in their third stage of development. 
4.1.5 Critical from premodal to dynamic meaning. The last adjective studied in detail here is critical. I will propose that in its development from premodal to dynamic meaning two stages can be distinguished. These are the result of one semantic change, which involves semantic generalization and leads from its original meaning immediately to dynamic meaning. As put forward in Table 5, this change does not involve a shift in the configuration of the semantic properties of relationality and potentiality. It will also become clear that the development of critical has much in common with that of crucial discussed above.

Table 5: The development of critical from premodal to modal meaning

\begin{tabular}{lccc}
\hline Stages & $\rightarrow$ & $\begin{array}{c}\text { stage } 1: \\
\text { original meaning }= \\
\text { collocational meaning }\end{array}$ & $\begin{array}{c}\text { stage 2: } \\
\text { dynamic meaning }\end{array}$ \\
\hline First attestation & $\rightarrow$ & $\begin{array}{c}\text { critic: } 1544 \\
\text { critical: } 1601\end{array}$ & $\begin{array}{c}(1664) \\
\text { roughly 1990 (CB) }\end{array}$ \\
\hline $\begin{array}{l}\text { Meaning and } \\
\text { examples }\end{array}$ & $\rightarrow$ & $\begin{array}{c}\text { 'necessary to determine the } \\
\text { direction of the disease' } \\
(25)-(27)\end{array}$ & $\begin{array}{c}\text { 'decisive for'; } \\
\text { 'important for' } \\
\text { relationality } \\
\text { potentiality }\end{array}$ \\
\hline
\end{tabular}

The first attestation of critical in English dates from 1590, and is a derivation of the now obsolete adjective critic (OED, s.v. critical). Around the end of the $16^{\text {th }}$ century, English critical has two distinct meanings. One is related to the act of judging, and can be paraphrased by 'given to judging', especially 'given to adverse or unfavourable criticism' (OED, s.v. critical). Its first attestation in the OED comes from Shakespeare and is given in (25). In its second sense, critical is a medical term and relates to the crisis or turning point of a disease (OED, s.v. critical; Barnhart 1988: 236a). An example of this medical sense is given in (26). This sense is also the meaning of critic in its first attestation, which is given in (27). 
(25) That is some Satire keene and criticall. (OED 1590 Shakespeare, A midsommer nights dreame V. i. 54)

(26) Who will say that the Physition in his iudgement by vrine, Who will say that the physician in his judgement by urine, by indicatorie and criticall daies, by Symptomes and other arguments by indicatory and critical days, by symptoms and other arguments ... doeth intrude into the secret prouidence of God? ... does intrude into the secret providence of God?

'Who will say that the physician in his judgement by urine, by indicatory and critical days, by symptoms and other arguments, intrudes into the secret providence of God?' (OED 1603 Heyden, An astrological discourse in justification of the validity of astrology. i. 19)

(27) If it appeare in the vj day, being aday iudiciall or creticke of the ague. if it appear in the $6^{\text {th }}$ day, being a day judicial or critic of the ague. 'If it [jaundis, OED] appears on the sixth day, being a judicial or critic day of the ague [i.e. an acute or violent fever, AVL].' (OED 1544 Phaer, Goeurot's [J.] Regiment of life $[1553] \mathrm{Gjb})$

As the sense of critical in (25) does not play a role in its semantic development of modal meaning, I will not discuss it in more detail. The medical sense of critical (and critic), illustrated in (26) (and [27]), however, did play an important role in the development of deontic meaning, and it is taken here as the first stage (cf. Table 5). ${ }^{20}$ This sense originates in the writings of Hippocrates (c460-377 BC), and refers to a changing point of a disease, a "sudden change for better or worse" (Liddell et al. 1951

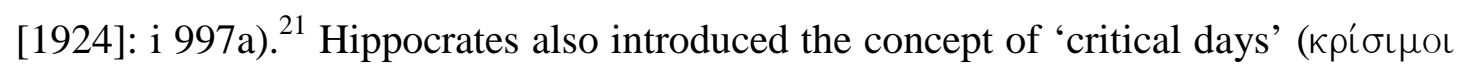




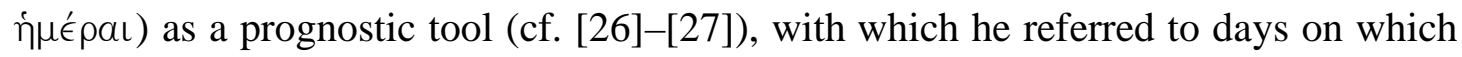
the illness reaches a crisis, and "which afforded and required a judgement (also

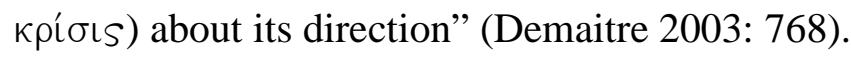

In his works De crisi and De diebus creticis, Galen provides the Hippocratic doctrine of critical days with a theoretical — astrological — foundation. He argues that critical days need to be calculated on the basis of a "medicinal month", which derives from the orbit of the moon (Siraisi 1990: 135). Since Galen, therefore, the meaning of critical in the collocation critical days also involves an astrological component. Moreover, several studies have shown that the Galenic idea of iatromathematics or astrological medicine has been kept in use throughout the Middle Ages (e.g. Demaitre 2003), the Early Modern period (e.g. Roos 2000), and even the Late Modern period (e.g. Harrison 2000). Hence, it is not surprising that the first attestations of $\operatorname{critic}(\mathrm{al})$ in its medical (and astrological) sense typically collocate with days, as in (26) and (27) above. A later example is given below.

(28) Another time is called Intercidental, which is a time falls out between the Judicial dauyes and Critical. (OED 1651 Culpepper, Semeiotica Uranica; or, an astrologicall judgment of diseases 22)

In collocation with day(s), critical functions as a classifier, indicating a specific subtype of day, rather than attributing a gradable quality to its referent. The types of days critical ones are opposed to are intercidental and judicial or indicatory days, as in (26) and (28).

The explanation of critical days above has shown that this fixed phrase has relational and potential meaning as a whole (cf. Table 5), just like the phrases crucial 
instance and crucial experiment in Section 4.1.4 above. In fact, critical days can be paraphrased as days that are necessary to determine the direction of the disease, just like a crucial experiment is necessary to determine the 'direction' of a scientific theory. This condition-goal paraphrase thus implies that the collocation studied here involves situational dynamic meaning.

The semantic change of critical that leads to its dynamic meaning involves semantic generalization through the expansion of the host-class. The data show that the use of critical is extended from the technical medico-astrological sense relating to the crisis in a disease to the more general meaning of 'decisive for' or 'important for' when used in modifying other nouns, just like crucial after its semantic generalization. In this extended sense, it is critical itself that has relational and potential meaning, and not critical in combination with the noun it classifies. What is regarded as critical has a decisive impact on the following course of events or, in other words, will determine the outcome of the matter talked about. The relationship established by critical is thus one of decisive influence or determining importance. The semantic generalization of critical has structural correlations in that it is able to take complements (see [29]-[31] below) - unlike in its collocational sense, as has been observed for crucial (cf. Section 4.1.4). Syntactically it does not function as a classifier anymore, but rather as an attribute, since it can be graded, as is illustrated in (29), and used in predicative position, as is illustrated in (30) and (31).

(29) Acquaint them [tender-plants, OED] gradually with the Air for this change is the most critical of the whole year. (OED 1664 Evelyn, Kalendarium hortense [1729] 198) 
(30) The short scenes are critical to providing continuity and maintaining suspense and eye-catching details include flickering/strobe lighting and even silhouetted shadows for the bedroom scene (...). (CB 1993, ukmags)

(31) The demands imposed by Formula One are greater than ever, he says (...). The cars too, have become more difficult to handle: "It is critical to get the set-up right because it is so easy to lose it in a big way." (CB 1996, times)

In (29), critical is modifying this change (presumably the change between two seasons) and it is graded. The adjective has the meaning of 'decisive for', but arguably the sense of necessity is not that clearly present. In fact, all Early and Late Modern English examples are similar to (29), with critical modifying a special occasion or period of time. It is only in Present-day English that critical appears in expressions in which the sense of necessity is foregrounded as well, as in examples (30) and (31). In (30), the use of short scenes is critical or necessary to provide continuity and maintain suspense in the play. This condition-goal paraphrase, typical of dynamic meaning, also applies to (31). Here, getting the set-up of a Formula One car right is critical or necessary to take a good start in a race (and ultimately, to win the race). Note that in this example, the condition is encoded by a clausal complement. In these two cases, some action is regarded as critical or necessary to the achievement of a particular goal, on the basis of SoA-internal grounds. These examples hence show that the first modal meaning critical develops is that of situational dynamic meaning, much like essential, vital and crucial.

In conclusion, critical develops dynamic modal meaning from its original medical-astrological meaning through semantic generalization. From its specific meaning of 'necessary to decide on the direction of the disease' in collocation with 
days, it develops the more general meaning of 'decisive for'. Both stages involve relational and potential meaning. In the dynamic modal stage, the meaning of critical is very similar to that of crucial in its fourth stage. It should be noted, though, that it is only in Present-day English that critical is used in clearly dynamic expressions, in which the necessity of SoAs is indicated on the basis of SoA-internal arguments.

4.1.6 A second pathway to dynamic meaning: crucial and critical. From the sections above, we can understand that the semantic developments of crucial and critical to (dynamic) modal meaning run parallel. They can be represented on a single pathway to dynamic meaning, as shown in Figure 2.

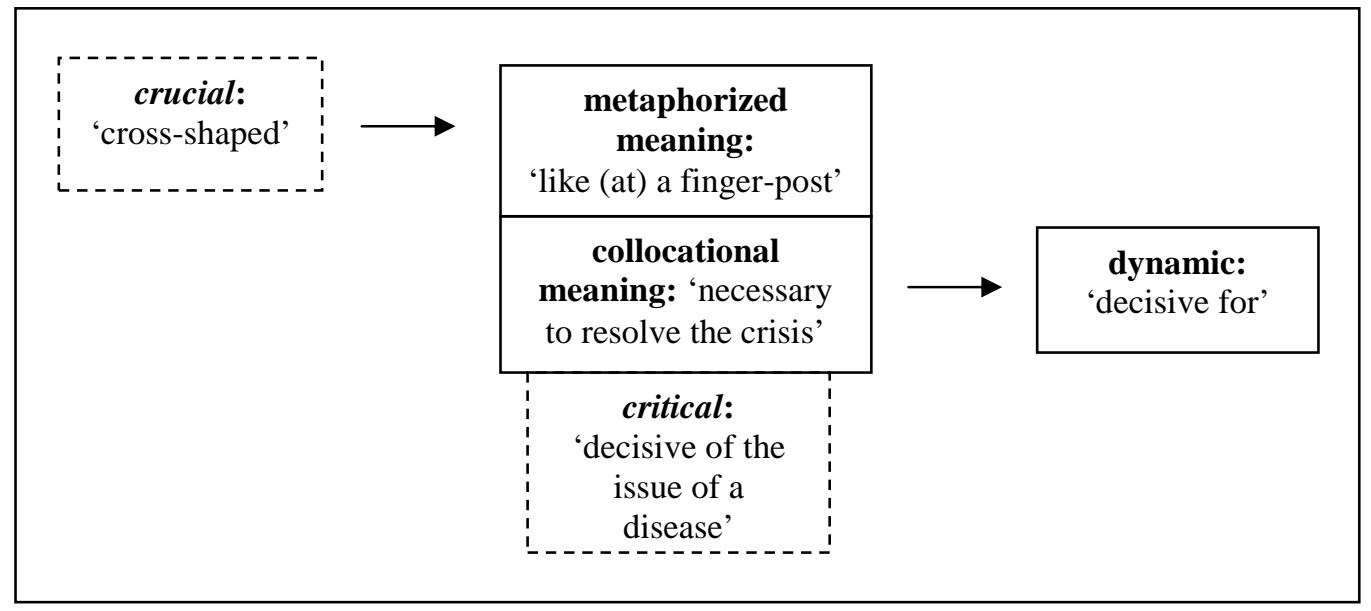

Figure 2: The second pathway to dynamic meaning: crucial and critical

Like in the case of the first pathway, the main differences between the two adjectives pertain to the initial stages of the respective developments. Crucial first underwent metaphorical projection before it could be used in its collocational meaning (as in crucial experiment), whereas with critical the stage of collocational meaning (critical days) coincides with its original stage. Importantly, in both cases the collocational stage involves the notion of a crisis or turning point. In the case of crucial, the crisis 
relates to the development of a scientific theory, while in the case of critical, the crisis relates to the development of a disease. After the stage of collocational meaning, both adjectives develop dynamic meaning through generalization. Semantically, the type of relationship they establish then relates to the notion of a crisis, and can be paraphrased as 'decisive for'. This change is also reflected structurally in that the adjectives can take complements (unlike in their collocational stages) (cf. vital in its generalized meaning, see Section 4.1.2). Syntactically, the adjectives no longer function as classifiers, but as gradable attributes, typically allowing for totality modifiers and predicative alternation. Thus, like in the case of essential and vital, the properties of relationality and potentiality can be seen as the semantic conditions for dynamic meaning, indicating necessity inherent in a situation. More specifically, we can conclude that crucial and critical illustrate a second pathway from premodal to (dynamic) modal meaning via the notion of a crisis, which differs from the first pathway exemplified by essential and vital, involving the notion of defining necessity.

\subsection{Change within the modal domain}

Whereas essential, vital, crucial and critical show differences in their changes from premodal to modal meaning — however, these could be grouped two by two in terms of two pathways, the adjectives all show the same change within the modal domain. From the dynamic meaning described as endpoint of the pathways presented above, all cases develop deontic meaning. The dynamic-deontic development has also been noted for modal auxiliaries with some cross-linguistic frequency (cf. Bybee et al. 1994, Van der Auwera and Plungian 1998). Importantly, however, the type of dynamic meaning involved differs. Whereas the modal auxiliaries first undergo micro-changes within the dynamic domain from participant-inherent (ability) to 
participant-imposed meaning before developing deontic meaning (e.g., Van Ostaeyen and Nuyts 2004: 113), ${ }^{22}$ the adjectives studied here develop only one type of dynamic meaning which leads to deontic meaning, viz. situational meaning. While these dynamic adjectival expressions indicate necessities that are internal to the SoAs referred to, deontic expressions involve an attitudinal source (typically the speaker) in whose view a certain action is assessed as necessary or desirable on the basis of (moral) arguments that are external to the SoA (see Section 2). In this sense, the change from dynamic to deontic meaning involves the process of subjectification as defined by Traugott (1989: 35), in which "meanings tend to become increasingly based in the speaker's subjective belief state/attitude toward the proposition". Specifically, deontic expressions are subjective in that they enact the speaker's position with regard to the situation (cf. De Smet and Verstraete 2006: 387). ${ }^{23}$ The first deontic utterance appears with essential in the first half of the $19^{\text {th }}$ century, and is shown in (32). Examples (33) to (35) illustrate deontic uses of vital, crucial and critical, only found in the Present-day English data.

As can be seen in (35), in their deontic meaning the adjectives are still gradable, since they can combine with the totality modifier absolutely — just like in their dynamic meaning. However, in their change from dynamic to deontic meaning, the adjectives also change in the type of opposition they imply (cf. Paradis 2001: 51-54). In dynamic uses, the adjectives are complementaries, "conceptualized in terms or “either ... or'” (Paradis 2001: 52) (either necessary or not necessary/avoidable). In deontic uses, by contrast, the adjectives are antonymic and they imply a scale (in this case one of [moral] desirability), on which they appear at one extreme (with at the other end adjectives such as, e.g., unacceptable). According to the types of gradable adjectives proposed in Paradis (2001: 51-54), they thus change from 'limit adjectives' 
to 'extreme adjectives', which is a shift from non-scalar to scalar. Therefore, they confirm Paradis's (2001: 58) finding that adjectives tend to get scalar interpretations.

(32) The Anglo-Catholics consider it essential to be ordained by bishops receiving their appointment in regular succession from the apostles. (OED 1842 Gell, Serm. Visitation Archdeacon of Derby 33)

(33) It is vital that the European Community helps the process of transition to market economies, preparing these countries for eventual EC membership. (CB 1992, ukephem)

(34) With the scourge of illegal narcotics infecting every part of the world, it is crucial to educate young people about the dangers of drugs. (CB 1998, sunnow)

"The most important thing is to sharpen the focus of the young generation so that they are better able to identify racism and totalitarianism in its early stages," he said. "In the battle against this fundamental evil of the twentieth century, it is absolutely critical to mount a timely resistance." (CB 1996, times)

As the diachronic corpora provide too few examples of deontic expressions, we can only start from the synchronic data to hypothesize how the change took place, i.e. how the process of subjectification worked. Since situational dynamic and deontic expressions merely differ in the presence or absence of an attitudinal source (see also Van linden 2009: 283-209), it is the interpretation of the presence of an attitudinal source that must have arisen as an invited inference. Crucially, this presence need not 
be overtly or structurally marked in the complement constructions studied here. Therefore, it may be argued that the invited inference arose in the following contexts.

(36) This should make you want to go to the toilet frequently. Although it may sting the first few times you go, this usually gets better the more water you pass. It is essential to keep emptying the bladder if you are to flush out the germs. (CB 1992, ukepehm)

(37) We must persuade our mps to support the Bill - it's a Private Member's Bill, and so it is essential that at least 100 MPs support it, or it will get thrown out without a second reading. (CB 1995, ukephem)

Example (36) repeats (2) above. In Section 2, I argued that the necessity expressed by its condition-goal structure resides in the nature of things, viz. the physical make-up of the urinary system. The structure in (37) indicates the need to have the support of 100 MPs in order to give the Wild Mammals (Protection) Bill a second reading (which is ultimately needed to have the bill passed). Here, the necessity expressed by the condition-goal structure resides in a self-imposed system, viz. the parliamentary system of Great Britain. In both examples, however, it is possible to see involvement of an attitudinal source. Example (37) can be interpreted as 'within the parliamentary system it is necessary that at least 100MPs support the bill to give it a second reading, and I think it is essential that this happens, because I feel it is highly desirable that we protect wild animals'. (36) can be understood as 'it is essential to keep emptying the bladder if you are to flush out the germs, and I think you should flush them out because you should keep yourself in good health'. In the clearly deontic examples given in (32) to (35), however, the necessities cannot be felicitously interpreted to 
reside in the nature of things or in a self-imposed system anymore. This is especially clear in (32), in which the necessity is related to the syntactic subject of the complex transitive matrix construction (the Anglo-Catholics). Note also that the expressions in (32) to (35) do not (implicitly or explicitly) refer to a concrete goal to which the SoAs expressed in the complements are said to be essential, vital, crucial or critical. Therefore, the examples show that the invited inference of the presence of an attitudinal source has semanticized or conventionalized (cf. Traugott 1989; Evans and Wilkins 2000: 549-550; Traugott and Dasher 2002: 34-40; Enfield 2003: 28-30): the more subjective scalar deontic meaning has become part of the meaning of the adjectives in addition their non-scalar dynamic meaning.

\section{Conclusion ${ }^{24}$}

In this article on the diachrony of modal expressions, I have elaborated on two topics which have received much attention in that domain, viz. sources of modal forms and pathways of change. Whereas these topics have typically been investigated on the basis of modal auxiliaries, both in language-specific and in cross-linguistic accounts, I have taken the perspective of an under-researched category in this domain, viz. adjectives. Even though the adjectives studied, viz. four borrowed items of Romance origin, belong to a different register than the modal auxiliaries, as rightly noted by a referee, they proved interesting and offered new insights, which are visualized in Figure 3.

Firstly, the adjectives focused on in this article, viz. essential, vital, crucial and critical, add new items to the lists of sources of deontic meaning presented in typological studies. As indicated in Figure 3, the adjectives derive from nouns that 


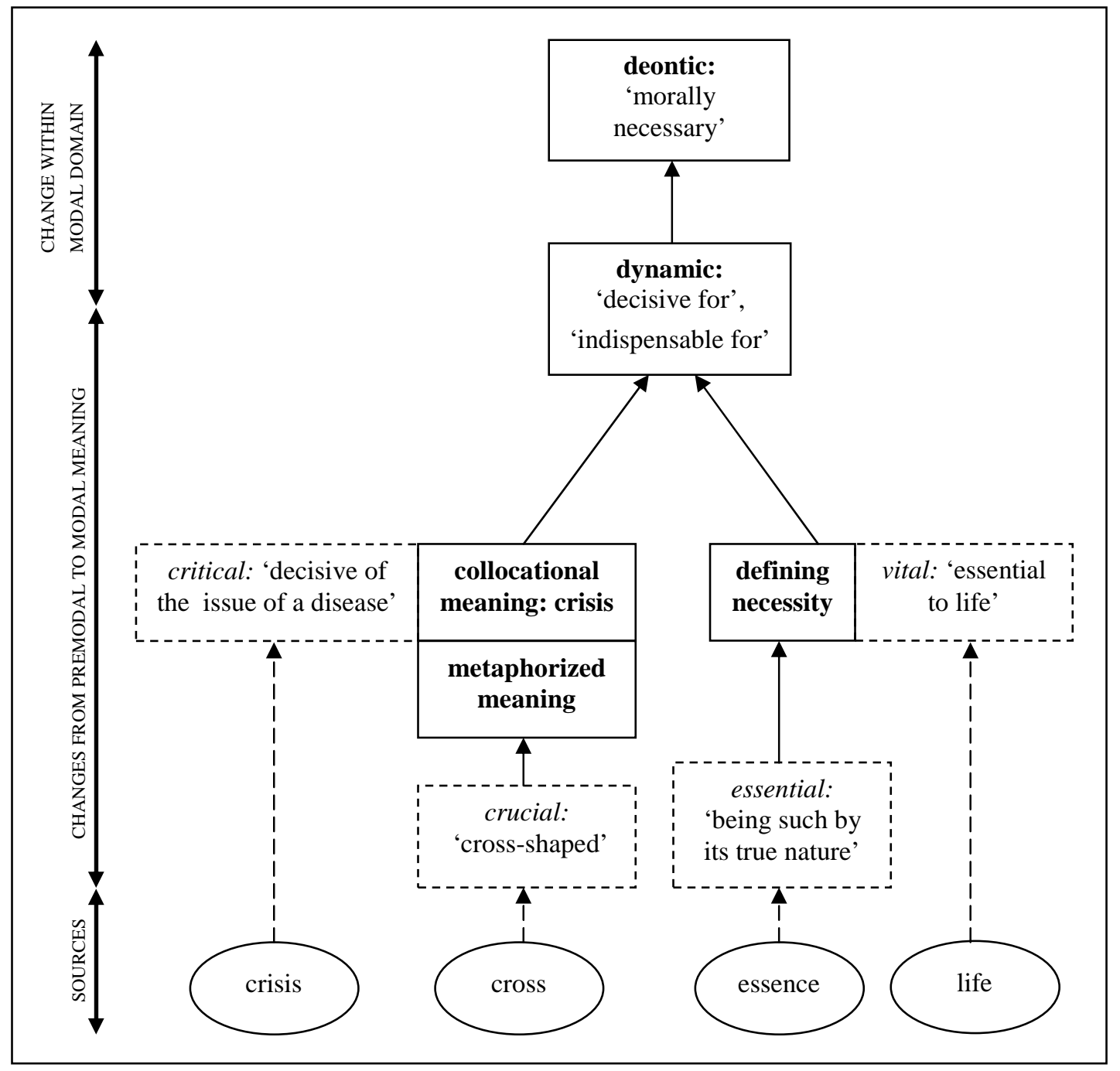

Figure 3: The sources and pathways of change of deontic adjectives

express abstract notions (crisis, essence, and life) or concrete objects (cross). It was also noted that many adjectives expressing a weak degree of desirability in the deontic domain, such as proper, appropriate, fitting and meet, by contrast, can etymologically be related to cross-linguistically recurrent sources of obligation or strong deontic meaning, such as possession and measure (Bybee et al. 1994: 182-183; Traugott and Dasher 2002: 118-119; Heine and Kuteva 2002: 333).

Secondly, this study of adjectives has expanded on well-known pathways of change. For one thing, it has adduced further evidence for the diachronic validity of 
the dynamic-deontic pathway, which has been proposed for modal auxiliaries already (e.g. Bybee et al. 1994: 191-194; Goossens 1999; Traugott and Dasher 20002: Ch. 3). Although the dynamic stages may differ for the verbal and adjectival expressions, as discussed in Section 4.2, in both cases the process of subjectification re-orients the property of necessity from the situation (necessity imposed by or internal to a particular situation) to the attitudinal source (necessity as judged by someone, typically the speaker, on the basis of SoA-external, moral principles). It should be noted, though, that subjectification is a metonymically based semantic process that does not systematically correlate with certain formal or structural properties. The diachronic analysis presented here therefore suggests that the distinction between dynamic and deontic modal meaning (in the upper part of Figure 3) may not always be clear-cut, unlike the stages in the developments from premodal to modal meaning.

What is even more interesting than the dynamic-deontic change within the modal domain, is the very changes from premodal to modal meaning. It is especially in this subdomain that the investigation of adjectives fills a gap in the literature. More specifically, it has been shown that with adjectives the development of (situational dynamic) modal meaning is a matter of the properties of relationality and potentiality. Relationality is needed to turn the adjective into a predicate of necessity that can link two concepts, for instance a part and a whole, or a condition and a goal. Accordingly, it was shown that relational meaning is the semantic condition for the development of potential meaning. Potentiality, in turn, is needed to ensure that the relationship established by the adjective is one of indispensability or decisive influence rather than intrinsic inclusion, and hence, that the necessity involved is dynamic-modal rather than defining. We can therefore assume that the semantic properties of relationality and potentiality are the conditions of entry into the modal domain. 
In addition, it became clear that the adjectives show some substantial differences in the development of these properties. Although in their original stages, they all function as classifiers, they differ in terms of the configuration of semantic properties. In particular, essential and crucial start off with non-relational and non-potential meaning, whereas vital starts off with relational meaning and critical even with both relational and potential meaning. It has also been shown that the factors driving the emergence of relationality can be quite different: patterns of co-occurrence with relational nouns in the case of essential, as opposed to metaphorical projection, metonymy and semantic generalization in the case of crucial. For the emergence of potential meaning, the same mechanisms were invoked in the case of crucial, whereas in the case of critical, only the mechanism of semantic generalization (through expansion of the host-class) applied. In the cases of essential and vital, by contrast, potential meaning emerged through patterns of co-occurrence with evaluative adjectives and potential actions. These mechanisms all indicate the importance of constructions in the development of a particular lexical item. We can thus conclude that the developments of the properties of relationality and potentiality, which themselves are new in the diachronic research of modal categories, involve more general mechanisms of change which are not that new, but have already been invoked for a varied set of semasiological extensions in distinct conceptual categories (cf. Geeraerts 1997: 93-102).

Still with regard to the properties of relationality and potentiality, it can be argued that they function on different levels: the development of relationality seems to be mainly a lexical matter, while the development of potentiality seems to be on a constructional rather than a lexical level. In the cases of essential and crucial, for instance, the change from non-relational to relational meaning involves the largest 
semantic leap (from meanings that do not involve necessity to meanings that do). Moreover, the emergence of relationality precedes the development of potentiality, most clearly so in the semantic extension of essential and vital. The changes involving potential meaning, and further on to deontic meaning, by contrast, involve smaller semantic developments (from one type of necessity to another).

Most importantly, this study has generalized over the differences in the development of the semantic properties of relationality and potentiality, and it has presented two distinct pathways of change from premodal to modal meaning, as shown in Figure 3. One pathway involves the notion of defining necessity and is followed by essential and vital. The second pathway involves the notion of a crisis, and is followed by crucial and critical. From a broader perspective, the two pathways can also serve as the basis of a more elaborate typology of pathways to deontic meaning. In this article, a few concepts were introduced that may prove useful in further explorations of the diachrony of modal categories, such as the features of relationality and potentiality. Apart from the borrowed adjectives discussed in this article, it may be interesting to look at native adjectives also, such as needful, which may present us with yet other pathways to deontic meaning (from 'poor, needy' over 'necessary, indispensable' [OED, s.v. needful] to 'morally desirable'). It is hoped that further research can expand this preliminary typology of adjectival pathways to deontic meaning. However, before we can build on this typology, we need to strengthen its foundations by adducing quantitative evidence for the developments proposed in this article, drawn from larger datasets.

Other questions for further reflection, as suggested by a referee, may include the application of the concepts of relationality and potentiality to other categories than adjectives, such as, for instance, the modal auxiliaries. If we take a closer look at the 
premodal stages of the modals, can we draw parallels with the adjectives? Or can we perhaps draw cross-linguistic parallels?

Finally, another concept that deserves further investigation is that of gradability. In the developments of the adjectives, we noted a change from non-gradable classifier uses to gradable attribute uses, which is consistent with the unidirectional tendency posited by Paradis (2001: 58). Within the modal domain, we noted a further change from limit adjectives to extreme adjectives, or from non-scalar to scalar gradable items. This finding also complies with the observation that adjectives tend to develop scalar interpretations (Paradis 2001: 58). Perhaps the study of adjectives in other modal domains, such as certain or true in the epistemic domain, may reveal similar changes and thus present us with other contexts in which shifts from non-gradable to gradable take place.

\section{Notes}

* The research reported on in this article has been made possible by research grants OT/03/20/TBA, OT/04/12 and OT/08/011 of the Research Council of the University of Leuven, as well as the Interuniversity Attraction Poles (IAP) Programme - Belgian State - Belgian Science Policy, project P6/44 Grammaticalization and (inter)subjectification. In addition, it has been supported by the Spanish Ministry of Education and Science (grant no. HUM2007-60706/FILO) and the European Regional Development Fund. I would also like to thank Jean-Christophe Verstraete for the fruitful discussions of topics covered in this study, and for his helpful comments on earlier versions of this article. Finally, I am indebted to the two anonymous referees and one of the Associate Editors of Cognitive Linguistics for their very generous and insightful remarks. Needless to say, I am the only one responsible for remaining errors of thought in the final version. Author's affiliation: Department of Linguistics, University of Leuven. Author's postal address: Department of Linguistics; University of Leuven; Blijde-Inkomststraat 21; Postbus 3308; 3000 Leuven; Belgium. Author's e-mail address: <an.vanlinden@arts.kuleuven.be>. 
${ }^{1}$ Of course, as suggested by a referee, other scholars have already pointed out that adjectives can have modal meanings as well, such as Nuyts (2001) for Dutch waarschijnlijk and German wahrscheinlich (both 'probable'), and Shindo (2008) for clear. These adjectives, however, express epistemic meanings, whereas the adjectives focused on in this article express deontic meanings.

${ }^{2}$ Agent-oriented or root meaning includes ability, desire, root possibility, obligation and necessity (Bybee et al. 1994: 177-179).

${ }^{3}$ However, Narrog (2005) presents Japanese data which do not comply with the agent-oriented > epistemic pathway. Instead, he proposes an overarching tendency for modal expressions to change from event-oriented (largely identical with agent-oriented) to speaker-oriented meaning.

${ }^{4}$ As suggested by a referee, Depraetere and Reed (2006: 281-282) provide a useful overview of how dynamic modality is treated in the literature.

${ }^{5}$ Likewise, the expressions for obligation in Chepang (Sino-Tibetan) and Temne (Niger-Congo) as well as the English semi-modals have to and have got to, and the Spanish forms haber de and tener que also derive from the notion of possession (Bybee et al. 1994: 182-184).

${ }^{6}$ In addition, the expression for obligation in Danish (må) (Bybee et al. 1994: 182) and the English modal auxiliary *motan (Traugott and Dasher 2002: 122) also derive from the notion of measure, just like the Dutch past participle gepast and its German counterpart angemessen (both 'fitting'). In Dutch, the present participle of the same verb passen ('fit'), viz. passend, can also be used to translate fitting.

${ }^{7}$ The Old French period is generally taken to last until 1350, so it possible that vital was borrowed from continental Old French. However, in view of the sociolinguistic situation in Britain during the Middle English period, it is more likely that vital was borrowed from Anglo-Norman than from Old French, if the source is not Latin (see Rothwell 1998).

${ }^{8}$ As noted by a referee, these sources are non-native from the perspective of English. Therefore, the adjectives belong to a different register than the English modal auxiliaries, which can be traced back to cross-linguistically recurrent sources. I will briefly return to this issue in Section 5.

${ }^{9}$ This section is based on Van linden et al. (2008: 231-240).

${ }^{10}$ Classifiers can be opposed to attributes, which assign a (typically gradable) quality to the instance referred to by the NP, as new in a new car, or beautiful in a beautiful car) (Bolinger 1967: 14-20; Teyssier 1968: 225-249; Halliday 1994: 184-186). Unlike attributes, classifiers can only occur in prenominal position and never appear predicatively. Further, since classifiers do not attribute a quality 
to the referent of the NP, but rather modify the reference of the head noun (Bolinger 1967: 14-15), they are not gradable, i.e., they “do not accept degrees of comparison or intensity” (Halliday 1994: 185).

${ }^{11}$ Relational nouns like these are different from other nouns in that they make schematic reference to another thing (the whole), and have the conception of a relationship with this other thing as a background (the part-whole relationship), just like the noun father (the male parent) makes schematic reference to offspring on the basis of the parent-offspring relationship (cf. Langacker 1991: 38-39).

${ }^{12}$ Note that this is highly determined by the speaker's Weltanschauung. An ancient Greek speaker, for example, would not see mercy as an essential attribute of god (e.g., Zeus).

${ }^{13}$ In their typology of subjectivity, De Smet and Verstraete (2006: 387) term this type of subjective meaning "ideational semantic subjectivity". This type is different from the subjective meaning conveyed in deontic expressions, which involves the enactment of the speaker's position towards the situation, and is labelled "interpersonal semantic subjectivity" in De Smet and Verstraete (2006: 386) (see Section 4.2).

${ }^{14}$ In the data, the earliest instances of vital in this more general meaning of 'essential to' are few. Therefore, the semantic developments proposed here are not necessarily consistent with the chronology of the attestations (cf. dates of first attestations in Table 3).

${ }^{15}$ However, as suggested by Hubert Cuyckens (pc), it might be argued that the collocation from which the process of generalization starts (viz. vital parts) provides a 'shortcut' to potential meaning, as it already indexes the property of potentiality. More precisely, the collocation can also be paraphrased as parts that are "necessary to life; performing the functions indispensable to the maintenance of life" (OED, s.v. vital). This potential element can be thought of as an invited inference, which is later semanticized (Traugott and Dasher 2002: 34-40). Paraphrases involving potentiality can also be used for examples which are comparable to those in (16) and (17) above, but which involve more concrete noun referents that are heterogeneous in substance. Examples are given below.

(i) To preserve intact such vital parts as the machinery, magazines, and steering gear. (OED 1889 Welch, Naval Architecture 141)

(ii) Spring washers are less effective, but answer well enough for the less vital parts of the mechanism. (OED 1912 Motor Man. (ed. 14) 206)

In these examples, vital can be paraphrased as 'necessary to its proper working'. However, the fact that such examples are attested rather late (i.e., after the instances with evaluative adjectives and potential 
actions), and the prior occurrence of defining examples such as (16) and (17) above together suggest that vital developed along the same lines as essential. Of course, the invited inference of potential meaning may have paved the way for the constructions discussed here to emerge.

${ }^{16}$ This section is based on Van linden et al. (2008: 240-244).

${ }^{17}$ It can be argued that this metaphor has a metonymical basis, as the instances in question are not cross-like, but rather situated at crosses posted at bifurcations of the road. This relation of spatial contiguity thus serves as the base for the metaphor, which is in keeping with Barcelona's claim that the target and/or the source of a potential metaphor "must be understood or perspectivized metonymically for the metaphor to be possible" (Barcelona 2000: 31; italics his). I thank Hubert Cuyckens for pointing this out to me.

${ }^{18}$ The question whether the emergence of the metaphorized meaning in English is a language-internal development or the result of another borrowing does not concern us here.

${ }^{19}$ The Latin phrases appeared in earlier scientific or philosophical English writings (e.g., The gradual removal of these suspicions at length led me to the Experimentum crucis (OED 1672 Newton, Light \& Colours i); The Experimentum crucis or that Experiment, which points out the Way we should follow, in any Doubt or Ambiguity (OED 1751 Hume, An enquiry concerning the principles of morals V. ii. 84)).

${ }^{20}$ It is also in this sense that the adjective was borrowed first into Latin and later into French, English and German (FEW II2: 1354b-1355b; Koselleck 2006: 358-363).

${ }^{21}$ Such a crisis usually involves the sudden excretion of "bad humours", for instance through heavy sweat during fever, vomiting, diarrhea or menstruation (Siraisi 1990: 135).

${ }^{22}$ In their diachronic study of the Dutch modal kunnen ('can'), Van Ostaeyen and Nuyts (2004) argue on the basis of the distribution of ambiguous cases that deontic meaning seems to have developed from participant-imposed dynamic meaning, and epistemic meaning from situational dynamic meaning (2004: 52).

${ }^{23}$ In De Smet and Verstraete's (2006: 386) typology of subjectivity, this type of subjective meaning is called "interpersonal semantic subjectivity" (cf. Section 4.1.1, note 13).

${ }^{24}$ This section is based on Van linden et al. (2008: 244-245). 


\section{References}

Andersen, Henning. 2001. Actualization and the unidirectionality of change. In Henning Andersen (ed.), Actualization: Linguistic Change in Progress (Amsterdam studies in the theory and history of linguistic science. Series 4: Current issues in linguistic theory 219), 225-248. Amsterdam: John Benjamins.

Barcelona, Antonio. 2000. Introduction: The cognitive theory of metaphor and metonymy. In Antonio Barcelona (ed.), Metaphor and Metonymy at the Crossroads: a Cognitive Perspective (Topics in English linguistics 30), 1-28. Berlin: Mouton de Gruyter.

Barnhart, Robert K. 1988. The Barnhart dictionary of etymology. Bronx, NY: Wilson. Bolinger, Dwight. 1967. Adjectives in English: Attribution and predication. Lingua 18. $1-34$.

Bybee, Joan L., Revere Perkins \& William Pagliuca. 1994. The Evolution of Grammar: Tense, Aspect and Modality in the Languages of the World. Chicago: University of Chicago Press.

Coates, Jennifer. 1983. The Semantics of the Modal Auxiliaries (Croom Helm linguistics series). London \& Canberra: Croom Helm.

De Smet, Hendrik. 2005. A corpus of Late Modern English Texts. ICAME Journal 29. $69-82$.

De Smet, Hendrik. 2008. Diffusional change in the English system of complementation. Gerunds, participles and for...to-infinitives. Leuven: University of Leuven dissertation.

De Smet, Hendrik \& Jean-Christophe Verstraete. 2006. Coming to terms with subjectivity. Cognitive Linguistics 17. 365-392. 
Demaitre, Luke. 2003. The Art and Science of Prognostication in Early University Medicine. Bulletin of the History of Medicine 77. 765-788.

Denison, David. 2001. Gradience and linguistic change. In Laurel J. Brinton (ed.), Historical Linguistics 1999. Selected papers from the $14^{\text {th }}$ International Conference on Historical Linguistics, Vancouver, 9-13 August 1999, 119-144. Amsterdam: John Benjamins.

Depraetere, Ilse \& Susan Reed. 2006. Mood and modality in English. In Bas Aarts \& April McMahon (eds.), The handbook of English linguistics (Blackwell handbooks in linguistics 21), 267-290. Oxford: Blackwell.

Diewald, Gabriele. 1999. Die Modalverben im Deutschen: Grammatikalisierung und Polyfunktionalität (Reihe Germanistische Linguistik 208). Tübingen: Max Niemeyer Verlag.

Enfield, Nicholas J. 2003. Linguistic epidemiology: Semantics and grammar of language contact in Mainland Southeast Asia (RoutledgeCurzon Asian linguistics series). London: RoutledgeCurzon.

Evans, Nicholas \& David Wilkins. 2000. In the mind's ear: The semantic extensions of perception verbs in Australian languages. Language 76. 546-592.

FEW: von Wartburg, Walther. 1922. Französisches Etymologisches Wörterbuch. Eine Darstellung des galloromanischen Sprachschatzes. Bonn: K. Schroeder.

Forrester, John M. 2002. The marvellous network and the history of enquiry into its function. Journal of the History of Medicine 57. 198-217.

Geeraerts, Dirk. 1997. Diachronic prototype semantics: A contribution to historical lexicology (Oxford studies in lexicography and lexicology). Oxford: Clarendon.

Goossens, Louis. 1983. Can and kunnen: Dutch and English potential compared. In Frans Daems \& Louis Goossens (eds.), Een spyeghel voor G. Jo Steenbergen: 
huldealbum aangeboden bij zijn emeritaat [a mirror for G. Jo Steenbergen: Festschrift offered on his retirement], 147-158. Leuven: Acco.

Goossens, Louis. 1985. Modality and the modals: A problem for functional grammar. In A. Machtelt Bolkestein, Casper de Groot \& J. Lachlan Mackenzie (eds.), Predicates and Terms in Functional Grammar (Functional grammar series 1), 203-217. Dordrecht: Foris.

Goossens, Louis. 1999. Metonymic bridges in modal shifts. In Klaus-Uwe Panther \& Gunter Radden (eds.), Metonymy in language and thought (Human cognitive processing 4), 193-210. Amsterdam: John Benjamins.

Halliday, Micheal A. K. 1994. An introduction to functional grammar. 2nd ed. London: Edward Arnold.

Hansen, Björn. 1998. Modalauxiliaire in den Slavischen Sprachen. Zeitschrift für Slawistik 3. 249-272.

Hansen, Björn. 2004. Modals and the boundaries of grammaticalization: The case of Russian, Polish and Serbian-Croatian. In Walter Bisang, Nikolaus P. Himmelmann \& Bjorn Wiemer (eds.), What makes grammaticalization? A look from its fringes (Trends in linguistics. Studies and monographs 158), 245-270. Berlin \& New York: Mouton de Gruyter.

Harrison, Mark. 2000. From Medical Astrology to Medical Astronomy: Sol-Lunar and Planetary Theories of Disease in British Medicine, c. 1700-1850. The British Journal for the History of Science 33 (1). 25-48.

Heine, Bernd, Ulrike Claudi \& Friederike Hünnemeyer. 1991. Grammaticalization: A conceptual framework. Chicago: University of Chicago Press.

Heine, Bernd \& Tania Kuteva. 2002. World lexicon of grammaticalization. Cambridge: Cambridge University Press. 
Klein, Ernest. 1971. A comprehensive etymological dictionary of the English language dealing with the origin of words and their sense development, thus illustrating the history of civilization and culture. Amsterdam, London \& New York: Elsevier Publishing Company.

Knoeff, Rina. 2004. The reins of the soul: The centrality of the intercostal nerves to the neurology of Thomas Willis and to Samuel Parker's theology. Journal of the History of Medicine and Allied Sciences 59 (3). 413-440.

Koselleck, Reinhart. 2006. Crisis. Journal of the History of Ideas 67 (2). 357-400.

Kratzer, Angelika. 1978. Semantik der Rede: Kontexttheorie, Modalwörter, Konditionalsätze (Monographien Linguistik und Kommunikationswissenschaft 38). Königstein/Ts.: Scriptor.

Langacker, Ronald W. 1991. Foundations of Cognitive Grammar, Vol. 2. Descriptive application. Stanford: Stanford University Press.

Liddell, Henry G., Robert Scott, Henry S. Jones \& Roderick MacKenzie (eds.). 1951 [1924]. A Greek-English lexicon. $9^{\text {th }}$ ed. compl., repr. Oxford: Clarendon.

Lyons, John. 1977. Semantics. Vol. 2. Cambridge: Cambridge University Press.

Narrog, Heiko. 2005. Modality, mood, and change of modal meanings: A new perspective. Cognitive Linguistics 16 (4). 677-731.

Nuyts, Jan. 2001. Epistemic modality, language, and conceptualization: A cognitivepragmatic perspective (Human cognitive processing 5). Amsterdam: John Benjamins.

Nuyts, Jan. 2005. The modal confusion: On terminology and the concepts behind it. In Alex Klinge \& Henrik Høeg Müller (eds.), Modality: Studies in form and function, 5-38. London: Equinox. 
Nuyts, Jan. 2006. Modality: Overview and linguistic issues. In William Frawley (ed.), The expression of modality (The expression of cognitive categories 1), 1-26. Berlin: Mouton de Gruyter.

Oxford English Dictionary: http://dictionary.oed.com/cgi/.

Palmer, Frank Robert. 1979. Modality and the English modals (Longman linguistics library). London: Longman.

Palmer, Frank Robert. 1986. Mood and Modality (Cambridge textbooks in linguistics). Cambridge: Cambridge University Press.

Palmer, Frank Robert. 1990. Modality and the English modals (Longman linguistics library). $2^{\text {nd }}$ ed. London: Longman.

Paradis, Carita. 2001. Adjectives and boundedness. Cognitive Linguistics 12 (1). 4765.

Perkins, Michael R. 1983. Modal expressions in English (Open linguistics series). London: Pinter.

Plank, Frans. 1984. The modals story retold. Studies in Language 8. 305-364.

Roos, Anna M. 2000. Luminaries in medicine: Richard Mead, James Gibbs, and solar and lunar effects on the human body in Early Modern England. Bulletin of the History of Medicine 74. 433-457.

Rothwell, William. 1998. Arrivals and departures: The adoption of French terminology into Middle English. English Studies 79 (2). 144-165.

Shindo, Mika. 2008. From visual adjective to modalized intensifier: A cross-linguistic study of grammaticalization. Paper presented at New Reflections on Grammaticalization (NRG) 4, University of Leuven, 16-19 July. (Abstract at http://wwwling.arts.kuleuven.be/nrg4/_pdf/shindo.pdf) 
Siraisi, Nancy G. 1990. Medieval and early Renaissance medicine: An introduction to knowledge and practice. Chicago: University of Chicago Press.

Sweetser, Eve. 1990. From Etymology to Pragmatics (Cambridge studies in linguistics 54). Cambridge: Cambridge University Press.

Teyssier, Jacques. 1968. Notes on the syntax of the adjective in Modern English. Lingua 20. 225-249.

TLF: Trésor de la langue française. 1971-1994. Dictionnaire de la langue du XIXe et $d u X X^{e}$ siècle, 16 vols. Paris: Centre National de la Recherche Scientifique.

Traugott, Elizabeth Closs. 1989. On the rise of epistemic meanings in English: An example of subjectification in semantic change. Language 65 (1). 31-55.

Traugott, Elizabeth Closs. 2006. Historical aspects of modality. In William Frawley (ed.), The expression of modality (The expression of cognitive categories 1), 107139. Berlin: Mouton de Gruyter.

Traugott, Elizabeth Closs \& Richard B. Dasher. 2002. Regularity in Semantic Change (Cambridge studies in linguistics 97). Cambridge: Cambridge University Press.

Van der Auwera, Johan \& Vladimir Plungian. 1998. Modality's semantic map. Linguistic Typology 2. 79-124.

Van linden, An. 2009. Dynamic, deontic and evaluative adjectives and their clausal complement patterns: A synchronic-diachronic account. Leuven: University of Leuven dissertation.

Van linden, An, Jean-Christophe Verstraete \& Hubert Cuyckens. 2008. The semantic development of essential and crucial: Paths to deontic meaning. English Studies 89 (2). 226-247.

Van Ostaeyen, Gert \& Jan Nuyts. 2004. De diachronie van kunnen [the diachrony of kunnen ('can')]. Antwerp papers in linguistics 109. University of Antwerp. 
von Wright, Georg H. 1951a. Deontic Logic. Mind 60 (237). 1-15.

von Wright, Georg H. 1951b. An Essay in Modal Logic (Studies in logic and the foundations of mathematics). Amsterdam: North-Holland Publishing Company.

von Wright, Georg H. 1971. Norm and Action: A logical enquiry (International library of psychology, philosophy and scientific method). London: Routledge \& Kegan Paul. 